\title{
The Effect of Competitive Anxiety on the Injury Level of Student-Athletes of Karadeniz Technical University
}

\author{
Heidar Sajedi (Corresponding author) \\ Department of Physical Education and Sports Science \\ Agri İbrahim Cecen University, Agri, Turkey \\ Tel: 0090-546-461-3590Ｅ-mail: Heidarsajedi.phd@gmail.com \\ Fatih Kirkbir \\ Department of Sport Science \\ Karadeniz Technical University, Trabzon, Turkey \\ Tel: 0090-532-583-8212 E-mail: fatihkirkbir@ktu.edu.tr
}

Received: July 19, 2020 Accepted: August 20, 2020 Published: August 27, 2020

doi:10.5296/jei.v6i2.17365 URL: https://doi.org/10.5296/jei.v6i2.17365

\begin{abstract}
Psychological factors have been significantly confirmed in athletic performance, sports injury prevention, sports rehabilitation, and as an effective means of managing stress and anxiety in competitions. The aim of this study was to investigate the effect of competitive anxiety on the injury level of student-athletes of Karadeniz Technical University.

The method of this research is descriptive and correlational. The statistical population includes all athletes of Karadeniz Technical University, which are equal to 320 people. To determine the sample size, Cochran's sample size estimation formula was used and the number of samples was 175, the gender random sampling method selected. First, to report sports injuries to describe the extent of injuries in the limbs (upper limbs, lower limbs, and trunk) and different parts of the body (joints, muscles, and bones), the report form of sports injuries was used and SCAT questionnaire was used to measure competitive anxiety. We analyzed data using SPSS software. We used regression because of the normality of the data in competitive anxiety tests and the occurrence of sports injuries.

The research findings show that the average competitive anxiety of male athletes is 14.11 and the competitive anxiety of female athletes is 14.49 . Competitive anxiety also has a significant
\end{abstract}


positive effect on sports injury. The beta coefficient also shows that competitive anxiety predicts 0.33 changes in sports injury.

Therefore, it can be said that as the level of competitive anxiety of athletic students increases, so does their level of injury, and to control sports injuries, mental skills should be increased and we should control the competitive anxiety of athletes.

Keywords: Competitive anxiety, Sports injury, Athletes

\section{Introduction}

The impact of psychological factors on performing sports skills, prevention of sports injuries, sports rehabilitation, and as an effective tool for managing stress and anxiety in competitions has been confirmed by various researches. In general, the causes of injuries in athletes can be classified into both physical and psychological categories (Armatas et al., 2007).

In recent years, participation in competitive sports at the university level has increased significantly. Along with this increase, the prevalence of injuries has also increased compared to the past, so that today sports injuries and collisions are the principal reasons for disability in young athletes (Steffen et al., 2009). As a result, the demand for services provided by pathology and medical-sports specialists is increasing. Exercise-related injuries account for a high percentage of all injuries reported in medical centers during the year (Weinberg \& Gould, 2014). Research shows that 50 percent of college athletes suffer from some form of physical injury during a match season (Maddison \& Prapavessis, 2007).

Sports injuries are caused by a physical activity that is done to spend leisure time or a more specialized purpose. These injuries may also result from accidents or overwork (excessive activity) and are not necessarily different from injuries from non-athletic activities. Many sports injuries are insignificant and do not prevent ordinary athletes from engaging in daily activities. But for people who exercise seriously, daily activities are no longer the only issue. Injuries must be effectively treated to enable recreational activities at the earliest opportunity (Alizadeh et al., 2006).

Sports injuries are injuries that occur as a result of severe injuries or excessive and excessive stretching during sports movements and have a wide range in terms of type and location of the injury. Research shows that in most sports, most we relate injuries to the lower limbs (Abernethy \& Bleakley, 2007). Shojauddin et al. (2008) in a study of student-athletes showed that the lower limbs with $35.7 \%$ had the highest rate of injury, and the head and face with $11.27 \%$ had the lowest rate of injury. This information is vital for medical-athletic team members because they are responsible for the immediate care of athletes. Although the principal focus of these individuals should be on the prevention and treatment of physical injuries, it is important to be aware of athletes' mental states and how they relate to the context of their injuries (Glick \& Horsfall, 2001).

According to various studies, several psychological factors may play a role in sports injuries, the most important of which are highly competitive anxiety, low self-esteem, high stress, lifestyle changes, and reduced social support. Shahbazi et al. (2011) and Bigler et al. (2014) 
in their research confirmed the effect of psychological factors on sports injury. Also, some psychological factors strengthen and improve the performance of athletes; strengthening these factors reduces the risk of injury and speeds up the recovery process of sports injuries (Johnson, 2006). Some researchers believe that anxiety in sports competitions, anxiety, and mental states is related to the number of injuries, and factors such as violence, hostility, and negative mental states are effective in the severity of injury (Hardy, 1992).

In psychology, anxiety is the body's natural response to danger. Anxiety is not uncommon, it is unpleasant when the athlete is upset and anxious for no apparent reason, in which case he loses his efficiency and will be in great danger at the competition (Weinberg \& Gould, 2014).

Anxiety is one of the most controversial and important issues in psychology and affects all psychological and physical dimensions of human beings. All the humans have experienced anxiety. Some life events warn us we are in a dangerous situation. Under these circumstances, anxiety is a natural reaction, because the job of anxiety is to mobilize the body's defenses (Gunnoe et al., 2001).

Eskandari et al. (2016) concluded that there is a direct and significant relationship between the level of sports anxiety (physical, cognitive, and decentralization) and the total amount of sports injuries that occurred to athletes during competitions, as well as the past year. Gunnoe et al. (2001) reported in a study that players with acute anxiety are more likely to be injured and the percentage of different injuries is higher (Gunnoe et al., 2001). Rezaei (2005) has concluded in his research that there is a significant relationship between competitive anxiety and the prevalence of sports injuries in wrestling and handball. However, some research has shown that competitive anxiety does not affect sports injury, including Weiss (2003) and Smith et al. (1994) and Velayati et al. (2012).

We can associate anxiety with physical problems (physical anxiety) and have a negative effect on people's thinking and cognition (cognitive anxiety or worry) and can disrupt athletes' focus. Following this decrease in concentration, we expose athletes to injury (Weinberg \& Gould, 2014).

Due to the fact that studies on the relationship between competitive anxiety level and injury rate are very limited and also the need to conduct studies to examine injured and uninjured athletic students in terms of anxiety level, in this study, the effect of competitive anxiety on the injury level of student-athletes of Karadeniz Technical University has been investigated and its effect on the injury of athlete students has been studied.

\section{Method}

The method of this research is descriptive and correlational. The statistical population includes all athletes of Karadeniz Technical University, which are equal to 320 people. To determine the sample size, Cochran's sample size estimation formula was used and the number of samples was 175, the gender random sampling method selected.

In the first step, we measured the level of competitive anxiety of athletic students using the Sports Competitive Anxiety Questionnaire (SCAT). The SCAT sports Competitive anxiety is 
a test for measuring competitive anxiety in sports. The test was developed in 1976 by Martinez in the United States after five years of testing on 4,000 subjects. This questionnaire has 21 phrases for measuring 3 subscales of physical anxiety ( 9 articles), cognitive anxiety ( 7 articles), and decentralization (5 articles) (Wilson \& Syrotuik, 2000).

The validity and reliability of this test have been obtained, and several studies and researchers have reported the high validity and reliability of this test. For example, the research of Martens $(1977,1987)$ measured the validity and reliability of this test and stated that this questionnaire has acceptable standards for psychological tests.

In the second step, in order to evaluate sports injuries to describe the extent of injuries in the limbs (upper limbs, lower limbs and trunk) and different parts of the body (joints, muscles, and bones), the reporting form of sports injuries is used, and the required information is based on interviews with athletes and information on the type and severity of injuries were obtained according to their medical records. They compiled this form in a study by Rezaei (2005) and we reported its validity to be 0.78 . In this study, we recorded injuries that occurred during training or competition, during which the injured player could not participate in the training session or the next day's match of the team. At this stage, the coaches of the teams were asked to write about the injuries of the players in the injury registration form (Soligard et al., 2010).

Also, age, sex, injury status (competition or training), and sports were determined in the first questionnaire and descriptive statistics methods of competitive anxiety and prevalence were determined using SPSS software. Because of the normality of the data in psychological tests and the occurrence of sports injuries, regression was used.

\section{Results}

Table 1. Demographic information

\begin{tabular}{|l|l|l|l|}
\hline Var. & Age & Height & Weight \\
\hline Mean & 23.67 & 172.04 & 68.95 \\
\hline Standard deviation & 1.11 & 3.62 & 6.75 \\
\hline
\end{tabular}

According to the results of the table above, the average age of student-athletes is 23.67 , their average height is 172.04 and the average weight of student-athletes is equal to 68.95.

Table 2. Average and standard deviation of athletes' competitive anxiety in terms of gender

\begin{tabular}{|l|l|l|}
\hline Gender & Mean & Standard deviation \\
\hline Male & 14.11 & 1.19 \\
\hline Female & 14.49 & 1.27 \\
\hline
\end{tabular}




\section{Macrothink}

According to the results of the above table, the average competitive anxiety of male athletes is 14.11 and the competitive anxiety of female athletes is 14.49 .

Table 3. Summary of regression model the effect of competitive anxiety on sports injury

\begin{tabular}{|l|l|l|}
\hline $\mathrm{R}$ & $\mathrm{R}$ Square & Adjusted R Square \\
\hline .33 & .10 & .09 \\
\hline
\end{tabular}

According to the results of Table 3, the correlation coefficient between competitive anxiety and sports injury is 0.33 and the coefficient of determination is 0.10 . In other words, it can be said that 0.10 changes in sports injuries are determined by competitive anxiety and 0.90 are determined by other variables.

Table 4. The results of the simple regression equation effect of competitive anxiety on sports injury

\begin{tabular}{|l|l|l|l|l|l|l|}
\hline Sig. & $\mathrm{t}$ & Standardized Coefficients & \multicolumn{2}{|l|}{ Unstandardized Coefficients } & \multicolumn{2}{|l|}{ Model } \\
\cline { 3 - 6 } & & Beta & Std. Error & $\mathrm{B}$ & \multicolumn{2}{|l}{} \\
\hline .000 & 7.99 & & .121 & 1.021 & (Constant) & \multirow{1}{*}{1} \\
\hline .000 & 7.782 & .331 & .033 & .297 & Competitive anxiety & \\
\hline
\end{tabular}

According to the results of Table 4 and considering the significant level of test error for the confidence level of 0.95 , it can be said that competitive anxiety has a significant positive effect on sports injury. The beta coefficient also shows that competitive anxiety predicts 0.33 changes in sports injury.

\section{Discussion}

Research has shown that athletes who practice mental skills are less likely to be injured than other athletes. However, little research has been done on the level of competitive anxiety with the injury. Therefore, the aim of the present study was to investigate the effect of competitive anxiety on the injury level of student-athletes of Karadeniz Technical University.

According to the results of the research, competitive anxiety has a significant positive effect on sports injury. The beta coefficient also shows that competitive anxiety predicts 0.33 changes in sports injury. In other words, with the increase in the level of sports competition among Karadeniz Technical University sports students, the rate of sports injuries among them will also increase.

In general, research on psychological characteristics, especially in the field of sports and exercise, is controversial. 
Some researchers immediately linked psychological traits to athlete injury, and another group believed that it was not significant.

Shahbazi et al. (2011) examined the relationship between mental skills and sports injuries in athletes present at the Student Sports Olympiad and found a significant relationship between cognitive skills and sports injuries. Bigler et al. (2014) also stated in a study that there is a significant relationship between basic mental skills, psychosomatic skills, and cognitive skills with the number of injuries of football players. Also, Ivarsson and Johnson (2010) in a study conducted with the presence of 152 male and female football players, introduced psychological factors as predictors of sports injuries. Kleinert (2007) also stated that they can associate psychological and personality factors with the injury.

The results of the research are consistent with the results of Eskandari et al. (2016) research. In their study, they concluded that there was a direct and significant relationship between the level of sports anxiety (physical, cognitive, and decentralization) and the total amount of sports injuries that occurred to athletes during competitions and the past year. The results of the study are consistent with the findings of Gonavi et al. (2001). In one study, they reported that players with acute anxiety were more likely to be injured and that the percentage of various injuries was higher (Gunnoe et al., 2001). The results are also consistent with Rezaei's (2005) research findings, which show that there is a significant relationship between competitive anxiety and the prevalence of sports injuries in wrestling and handball. These results are consistent with Galambos et al. (2005) research and findings of Ford et al. (2000) research. Athletes with high levels of anxiety are more likely to be injured, they say.

However, the results of the study are not consistent with the findings of the Velayati study et al. Because in their research, they concluded that there was no significant difference between the mean score of competitive sports anxiety disorder of injured and uninjured elite basketball players. Therefore, it seems that competitive sports anxiety has nothing to do with sports injuries in Iran's elite basketball players.

Research shows that athletes need to have the necessary mental skills to deal with stress and anxiety, and athletes with high competency in controlling competitive anxiety are less likely to be injured than other athletes. Low anxiety can be helpful sometimes to compete with athletes and motivate competition, but increasing anxiety reduces balance, reduces coordination between body parts, and ultimately reduces concentration, which can lead to injury among athletes because of Losing balance and falling, colliding with the opposing player and twisting the leg and other limbs (Johnson, 2006).

A person with a high level of anxiety often behaves disproportionately in threatening situations, for example, it causes losing focus of the athlete, disrupting the regulation of a physical activity that is involved in the possibility of injury, and thus increasing the risk of injury (Nideffer, 1983).

In general, it can be said that if a person's perception causes an imbalance between needs and the person's ability to respond, he or she will feel fear, resulting in increased anxiety. With this increase, anxiety (cognitive anxiety), physiological activity (physical anxiety) peaks, and 
is accompanied by other responses such as changes in attention and concentration, and in general, all these factors lead to the disorder in the individual and Increasing the likelihood of injury for him. Despite all the facilities and conditions, there may still be a risk of injury, and any injury may have serious psychological consequences that can cause anxiety.

\section{Acknowledgments}

Therefore, ways to prevent injury and anxiety should be identified and we should take necessary measures in relation to them.

Given that it significantly related the level of sports anxiety in this study to the amount of sports injuries, we recommend it to reduce stress and reduce the extent of sports injuries by using stress management methods and controlling athletes' psychological factors. The ability to deal with psychological factors, including anxiety, is a neutralizing factor in reducing the risk of injury. Due to the fact that stressors may depend on the inside or outside of the exercise field, stress management mechanisms should be identified and applied. One of the basic and simplest neutralizers of stress management seems to be social support from special people. To this end, the level of awareness of coaches and those involved in sports should be increased in order to be aware of how to deal with the athlete and to avoid creating negative psychological and stress factors that may lead to injury.

Physical education teachers, sports injury specialists, and sports psychologists are also advised to use mental training and educational strategies to try to improve cognitive skills and reduce anxiety in athletic students, thus reducing the risk of sports injuries in them.

\section{References}

Abernethy, L., \& Bleakley, C. (2007). Strategies to prevent injury in adolescent sport: A systematic review. Br J Sports Med, 41, 627-38. https://doi.org/10.1136/bjsm.2007.035691

Alizad, M. H., Qara Khanlou, R., \& Daneshmandi, H. (2006). Prevention and treatment of sports injuries. Organization for the Study and Compilation of Textbooks (Samt) (pp. 1-10).

Armatas, V., Chondrou, E., Yiannakos, A, Galazoulas, Ch., \& Velkopoulos, C. (2007). Psychological aspects of rehabilitation following serious athletic injuries with special reference to goal setting: A review study. Physical Training, June(1). Retrieved July 12, 2007, from http://ejmas.com/pt/2007pt/ptartgalazoulas0707html

Bigler, K., Alizadeh, M. H., \& Khabiri, M. (2014). Investigating the Relationship between Psychological Skills and Injuries of Football Players of Tehrani Teams of Iran Premier League. Journal of Sports Medicine (Movement), 6(2), 89-102.

Eskandari, I., Ghaderian, M., \& Zolaaktaf, V. (2016). The relationship between the level of sports anxiety and the incidence of sports injuries in wrestling students. Journal of Sports Psychology, 5(13), 39-48.

Ford, I. W., Eklund, R. C., \& Gordon, S. (2000). An examination of psychosocial variables moderating the relationship between life stress and injury time-loss among athletes of a high standard. Journal of Sports Sciences, 18(5), 301-12. https://doi.org/10.1080/026404100 
402368

Galambos, S. A., Terry, P. C., Moyle, G. M., \& Locke, S. A. (2005). Psychological predictors of injury among elite athletes. British Journal of Sports Medicine, 39(6), 351-354. https://doi.org/10.1136/bjsm.2005.018440

Glick, I. D., \& Horsfall, J. L. (2001). Psychiatric Conditions in Sport. Physician and Sports Medicine, 29, 44-52. https://doi.org/10.3810/psm.2001.08.913

Gunnoe, A. J., Horodyski, M. B., Tennant, L. K., \& Murphey, M. (2001). The Effect of Life Events on Incidence of Injury in High School Football Players. J Athl Train, 36(2), 150-5.

Hardy, L. (1992). Psychological stress, performance and injury in sport. Br Med Bull, 48, 615-29. https://doi.org/10.1093/oxfordjournals.bmb.a072567

Ivarsson, A., \& Johnson, U. (2010). Psycholigcal factors as predictors of injuries among senior soccer players a prospective study. Journal of Sports Science and Medicine, 9, 347-352.

Johnson, U. (2006). Sport injury, psychology and intervention: An overview of empirical findings. Int J Sport Exercise Psychol, 57, 1-10.

Kleinert, J. (2007). Mood states and perceived physical states as short term predictors of sport injuries: Two prospective studies. International Journal of Sport and Exercise Psychology, 5(4), 340-351.

Maddison, R., \& Prapavessis, H. (2007). Preventing Sport Injuries: A Case for Psychology Intervention. In D. Pargman (Ed.), Psychological bases of Sport Injuries (pp. 25-38) Morgantown: Fitness Information Technology.

Martens R. (1977). Sport competitive anxiety test. Champaign, I: Human Kinetics Books.

Martens, R. (1987). Coaches' guide to sport psychology: A publication for the American Coaching Effectiveness Program: Level 2 sport science curriculum. Human Kinetics Books.

Nideffer, R. M. (1983). The injured athlete: Psychological factors in treatment. Orthopedic Clinics of North America, 14, 373-385.

Rezaei, M. (2005). Relationship between psychological factors (self-esteem, competitive adjective anxiety) and the prevalence of sports injuries in wrestling and handball (Master Thesis, University of Tehran, Iran).

Shahbazi, M., Vazini, T. A., \& Varhimizadeh, M. (2011). The relationship between the prevalence of sports injuries and psychological readiness of male and female students in the 10th Sports Olympiad of the country's students. Journal of Sports Medicine (Movement), 6, 125-144.

Shoja, A. D., Sadr, A. D., Alizadeh, M. H., \& Moradi, M., (2008). Investigation of the prevalence of sports injuries and traumatic factors in male students of Payame Noor University. Research in Sports Science, 19, 71-83.

Smith, A. M., \& Milliner, E. K. (1994). Injured athletes and the risk of suicide. Journal of 
Athletic Training, 29(4), 337-349.

Soligard, T., Nilstad, A., Steffen, K., Myklebust, G., Holme, I., Dvorak, J., ... Andersen, T. E. (2010). Compliance with a comprehensive warm-up program to prevent injuries in youth football. Br J Sports Med, 44(11), 787-93. https://doi.org/10.1136/bjsm.2009.070672

Steffen, K., Pensgaard, A. M., \& Bahr, R. (2009). Self-reported psychological characteristics as risk factors for injuries in female youth football. Scand J Med Sci Sports, 19(3), 442-51. https://doi.org/10.1111/j.1600-0838.2008.00797.x

Veleyati, R., Ghasemi, G. A., Rahimi, N., \& Movahedi, A. R. (2012). The Level of sport competitive anxiety in elite basketball players and and its relationship with sport injuries. Journal of Jentashapir, 3(2), 350-359.

Weinberg, R. S., \& Gould, D. (2014). Foundations of sport and exercise psychology. Champaign, II: Human Kinetics.

Weiss, M. R. (2003). Psychological aspects of sport-injury rehabilitation: A developmental perspective. Journal of Athletic Training, 38(2), 172-183.

Wilson, P., \& Syrotuik, D. G. (2000). Reexamining the factorial composition and factor structure of the Sport Anxiety Scale. Journal of Sport \& Exercise Psychology, 22, 183-193. https://doi.org/10.1123/jsep.22.2.183

\section{Copyright Disclaimer}

Copyright for this article is retained by the author(s), with first publication rights granted to the journal.

This is an open-access article distributed under the terms and conditions of the Creative Commons Attribution license (http://creativecommons.org/licenses/by/3.0/). 